\title{
DE VOLTA AO "TERCEIRO MILÊNIO”: CÍRCULOS SOCIAIS NA CONSTRUÇÃO DA UENF EM CAMPOS DOS GOYTACAZES ${ }^{1}$
}

Glauber Rabelo Matias ${ }^{(*)}$

Trato do processo de construção da Universidade Estadual do Norte Fluminense Darcy Ribeiro (UENF), sediada na cidade de Campos dos Goytacazes, no Norte Fluminense do Estado do Rio de Janeiro, com base nas “interações” e no entrecruzamento dos “círculos sociais” compostos por diversos personagens atuantes no cenário histórico de seu nascedouro, contextualizando tal surgimento institucional como um feito margeado por aproximações e distanciamentos de indivíduos e grupos, significantes da efetivação de um empreendimento público no mundo. ${ }^{2}$

A UENF foi inaugurada em 16 de agosto de 1993, sendo naquele momento a primeira universidade pública do município e da região constituída num campus a partir de cursos de graduação e de pós-graduação, a se desenvolver em todas as áreas do saber científico, como as Ciências Humanas, Biológicas, Agrárias e Tecnológicas. Sob o perfil institucional fundamentado a partir da tríade ensino/pesquisa/extensão, a UENF estaria voltada para o cultivo e a produção científica e tecnológica, contribuindo, de forma decisiva, para a superação dos problemas relacionados ao desenvolvimento regional e nacional (RIBEIRO, 1993).

A jovem universidade nasceu na área urbana do município de Campos - compreendida entre o $n^{\circ} 300$ e o $n^{\circ} 710$ da Avenida Alberto Lamego, no caminho que dá acesso ao litoral do município vizinho de São João da Barra - às margens do Rio Paraíba do Sul, sob edificações de concreto

\footnotetext{
${ }^{1}$ Este texto é produto intelectual de pesquisa de mestrado realizada entre março de 2007 e maio de 2009, com o auxílio de bolsa concedida pelo Conselho Nacional de Desenvolvimento Científico e Tecnológico (CNPq). A pesquisa esteve vinculada ao Programa de Pós-Graduação em Sociologia e Antropologia (PPGSA) do IFCS/UFRJ, sob orientação da Prof. ${ }^{a}$ Dr. ${ }^{a}$ Glaucia Villas Bôas.

${ }^{(*)}$ Doutor em Sociologia Política pelo Programa de Pós-Graduação em Sociologia Política da Universidade Estadual do Norte Fluminense Darcy Ribeiro (PPGSP/UENF), tendo realizado Pós-Doutorado pelo PPGSP/UENF (2018). Mestre em Sociologia (IFCS/UFRJ), Bacharel em Ciências Sociais (UENF), Licenciado em Ciências Sociais (UFF). E-mail: glauber_rabelomatias@yahoo.com.br.

${ }^{2}$ Para a consecução deste objetivo, a pesquisa lançou mão de pesquisa documental realizada no "Arquivo Darcy Ribeiro" localizada à época na Fundação Darcy Ribeiro (FUNDAR) no Rio de Janeiro, através da série "II Governo Brizola (1991-1994)", mais especificamente, da subsérie "UENF". Também foram realizadas entrevistas semiestruturadas com quatro personagens campistas, pioneiros da fundação da UENF: 1) Geraldo Augusto Venancio, professor da Faculdade de Medicina de Campos e ex-vereador municipal; 2) Maria Thereza da Silva Venancio, exdiretora da Faculdade de Filosofia de Campos e ex-professora da UENF; 3) Mário Lopes Machado, ex-professor da Faculdade de Filosofia de Campos, representante do Sindicato dos Professores de Campos e Macaé (SINPROCAM) na defesa da Emenda Popular, e funcionário técnico-administrativo da UENF; e, 4) Zuleima de Oliveira Faria, ex-diretora da Faculdade de Filosofia de Campos e ex-Coordenadora Acadêmica da UENF.
} 
armado, conhecidas noutra experiência da área educacional estadual, a dos Centros Integrados de Educação Pública (CIEPs). Contudo, seus marcos oficiais de fundação, reconhecidos na imagem de seus prédios, carecem ainda de uma compreensão sociológica sobre seus antecedentes imediatos no cenário local, com vistas a iluminar os debates acerca de sua recente história na cidade de Campos. ${ }^{3}$

Importa ressaltar que a versão final do projeto UENF foi publicamente formalizada através de seu “Plano Orientador” (RIBEIRO, 1993), assinado pelo antropólogo e educador Darcy Ribeiro, incumbido pelo então governador Leonel Brizola - em sua segunda passagem pelo Executivo Estadual do Rio de Janeiro, de 1991 a 1994 - a levar adiante o projeto de construção da UENF. O evento de fundação da universidade mostrava-se como pauta urgente daquele governo pedetista uma vez que deveria fazer cumprir o artigo $n^{\circ} 49$ das Disposições Constitucionais Transitórias que continha o verso sobre a criação da Universidade do Norte Fluminense pelo Estado, com sede em Campos, em um prazo máximo de três anos após a promulgação da Carta Magna do Estado do Rio de Janeiro de 1989.

A celeridade na empreitada de fazer nascer a UENF, como meta estabelecida pela Secretaria Extraordinária de Programas Especiais (SEEPE) do então governo Brizola, era justificada também por um parágrafo em especial do tal artigo constitucional que destacava a exiguidade dos prazos em voga, uma vez que, se até dezoito meses, após a data da Constituição, a Lei de Criação da UENF não fosse regulamentada, as unidades previstas passariam a ser de responsabilidade da Universidade do Estado do Rio de Janeiro (UERJ). O clamor pelo nascimento da universidade em Campos não encontrava apenas na letra fria que a projetou o seu elemento justificador. Devo demonstrar que correspondia antes a um anseio histórico dos círculos intelectuais e políticos da cidade, que fizeram constar esta demanda local no texto constitucional.

Sublinho, desta forma, que tal mecanismo jurídico que previa a construção da universidade em Campos estava significado por um episódio singular denominado "Campanha Popular em Defesa da Universidade” de 1989, quando os campistas lograram sistematizar a ambição em torno da universidade num movimento organizado, visando o recolhimento de assinaturas para substantivar o documento que seria entregue à Assembleia Legislativa do Rio de Janeiro (ALERJ), naquele ano. Tal acontecimento ficou conhecido como a "Emenda Popular" de 1989, levada a efeito durante o mandato estadual do governador Moreira Franco (1987-1990).

\footnotetext{
${ }^{3}$ Para este esforço, ressalto os trabalhos de Alves e Lima (2003); Smiderle (2004); Matias (2009); Smiderle e Muylaert (2013).
} 
Interessante notar que o projeto de universidade que constava no escopo da "Emenda Popular” de 1989 estava circunstanciado, a partir dos círculos intelectuais e políticos de Campos, pela proposta de criação de uma universidade pública para a cidade através da fusão das instituições de ensino superior de caráter privado, existentes na cidade, a saber: a Faculdade de Filosofia de Campos, criada em 1961, a Faculdade de Direito, de 1963, a Faculdade de Medicina, de 1966, e a Faculdade de Odontologia, construída em 1967. O projeto de universidade defendido pelos círculos campistas passava pela afirmação de um perfil institucional assentado nas carreiras mais tradicionais e pela formação profissional tendo em vista abastecer o mercado de trabalho local e regional, sob a rubrica de suas fundações mantenedoras: a Fundação Cultural de Campos, que geria as faculdades, de Filosofia, Direito e Odontologia, e a Fundação Benedito Pereira Nunes, responsável pela Faculdade de Medicina.

Nesse sentido, o momento de construção da UENF indicou, flagrantemente, o encontro de dois projetos de universidade basicamente diferentes: de um lado, a ideia de universidade, defendida pelos campistas que lutaram pela aprovação da Emenda Popular em 1989, com base na projeção de suas faculdades tradicionais, e de outro, a proposta assumida pela versão final do projeto, conduzida pela figura pública de Darcy Ribeiro, mediante um desenho de universidade que se proclamava como a "universidade do terceiro milênio" (RIBEIRO, 1993), já que propunha se vincular aos padrões internacionais do saber científico para superar as problemáticas inerentes à situação do “atraso histórico”, em níveis regional e nacional.

Objetivando uma compreensão mais rigorosa acerca do encontro de tão distintos projetos de universidade no seio da fundação da UENF, sigo a trilha analítica atenta à dinâmica das “interações” e dos “círculos sociais”, expressões encontradas na sociologia clássica de Georg Simmel (1939), representativas dos afastamentos e aproximações de grupos e personagens atuantes no período de nascimento da instituição. Penso ser fundamental observar os interesses, as articulações, as vontades manifestas por este ou aquele grupo, marcadas por feições tensas e controversas, de oposição entre aqueles, mas, sobretudo, de “interação”, conforme sugere a acepção simmeliana.

A indagação sociológica emergente desta questão é a seguinte: como ideias e posicionamentos diversos, a respeito da construção da universidade pública na cidade de Campos dos Goytacazes, estiveram em “interação” naquela moldura histórica? Noutras palavras: como se tornou possível a UENF em Campos? Uma sociologia dos “círculos sociais” a partir do caso UENF requer, como parte dos esforços para a sua confecção, a atenção às múltiplas interações componentes do panorama de sua época de construção, de modo a conseguir visualizar os grupos 
sociais participantes de tal cenário, suas motivações e posições a respeito da causa da universidade pública.

\section{UMA “SOCIOLOGIA DOS CÍRCULOS SOCIAIS” A PARTIR DE GEORG SIMMEL}

Georg Simmel (1939) aborda questões fundamentais da sociologia enquanto campo diferenciado do saber científico com o objetivo de sistematizar conceitualmente o universo do "social”, contribuindo assim para a fundamentação de uma "teoria do ser-sociedade na humanidade”. O autor observa a natureza particular do conhecimento sociológico, a partir das relações sociais mais finas que envolvem o "indivíduo” e a “sociedade”, em sua indivisibilidade empírica.

Nestes termos, Simmel (1939) salienta que a “sociedade” nasce dos indivíduos, ao passo que a noção de “indivíduo", tomada em sua acepção moderna, também emerge da sociedade, identificando com isto, a impossibilidade de dar primazia analítica a qualquer das duas dimensões, revelando a dificuldade de estabelecer uma antítese entre as noções de “indivíduo” e "sociedade”. Estas categorias comportam, ao ver do autor, conteúdos históricos relativos ao próprio processo de complexificação da vida social moderna, que modifica processualmente determinados parâmetros de compreensão, constituindo pontos básicos de sua teoria.

Conhecer os modos pelos quais determinadas "formas sociais" conseguem historicamente se manter e, neste particular, investigar como se fundamentam as "leis” próprias da "sociação" (vergesellschaftung) ${ }^{4}$ apresentavam-se como objetivos fundamentais da empreitada simmeliana. Deste modo, a compreensão acerca da indistinção empírica entre “forma” e “conteúdo” sociais, pode ser percebida na gênese do esforço do clássico alemão em captar, a partir de qualquer fenômeno social dado, que “[...] conteúdo e forma sociais constituem uma realidade unitária [...]” onde “[...] uma forma social desligada de todo conteúdo não pode ter existência, do mesmo modo que a forma especial não pode existir sem uma matéria da qual seja forma” (SIMMEL, 1894 apud MORAES FILHO, 1983a, p.61). O problema da sociologia como ciência, para Simmel, estaria configurado, por excelência, como a descoberta da permanência e das mutações das “formas

\footnotetext{
${ }^{4}$ O conceito de "sociação” é definido, em sua relevância teórico-metodológica, em “O Problema da Sociologia” (1894), como base para a distinção entre forma da "sociação” (ou "formas sociais”) e conteúdo da "sociação”, referindo-se enquanto "[...] conteúdo ou matéria da sociação tudo quanto exista nos indivíduos (portadores concretos e imediatos de toda realidade histórica) - como instinto, interesse, fim, inclinação, estado ou movimento psíquico - tudo enfim capaz de originar ação sobre outros ou a recepção de suas influências” (SIMMEL, 1894 in: MORAES FILHO, 1983a, p. 61).
} 
sociais”, a partir de distintos conteúdos sociais, submetendo os fatos históricos a uma nova abstração e ordenação.

É justamente com base na tentativa de construção destes recursos analíticos que se deve conceber a noção de “círculos sociais” no interior do arcabouço teórico de Simmel (1939). Penso ser metodologicamente relevante tal abordagem sociológica acerca das ideias e dos processos sociais, com vistas a superar dualismos de perspectiva concernentes às noções de "indivíduo e sociedade”, ou mesmo, de “forma e conteúdo”. Neste sentido, os “círculos sociais” são abstrações formuladas por Simmel para a observação das configurações sociais significadas pelas interações de cada indivíduo, tendo em vista o incessante fluxo histórico que fornece sentido às interações realizadas no mundo social. Simmel (1939) percebe, por exemplo, a noção de "círculos sociais” segundo a compreensão da formação da sociedade moderna, ao pontuar que a constituição de círculos pode explicar o grau de unidade que pressupõe o consenso e a discordância, as aproximações e os distanciamentos entre indivíduos, de acordo com o desenvolvimento das individualidades.

Assim, por exemplo, os “círculos sociais” podem ser visualizados a partir das características formativas dos grupos sociais, que distinguem os indivíduos quanto à origem e à posição social, desenhando uma espécie de estilo de vida singular baseado no critério da "honra" enquanto elemento formador da unidade de grupo: “A estreiteza dos laços que ligam os membros de cada círculo se pode medir pelo grau em que este círculo tem de formar uma "honra” especial, de maneira que a ofensa da honra por um dos membros seja sentida pelos demais como uma diminuição da própria honra [...]” (SIMMEL, 1939, p. 34).

Atento à análise dos “círculos sociais” como via de compreensão das relações entre "forma e conteúdo” sociais, Simmel (1939) demonstra que a presença de certa quantidade de círculos e da natureza de suas configurações (visto em suas interseções e entrecruzamentos) responderia pelo nível de complexificação de uma dada sociedade. A dinâmica que envolve o entrecruzamento dos círculos sociais indicaria a possibilidade de diferenciação social, tanto em relação à esfera individual quanto no que tange à estruturação dos grupos sociais, representando deste modo, uma forma de inferir o grau de flexibilidade ou de "rigidez” de uma estrutura social, que permaneceria paralelamente às variações sociais.

O desenvolvimento histórico da configuração dos “círculos sociais” foi visto por Simmel (1939) sob o ângulo dos “delicados fios” que constroem a esfera dos eventos cotidianos, algo imperceptível numa análise social apriorística, incorporando assim o curso dos acontecimentos que 
engendram as pequenas relações sociais, ao mesmo tempo em que são sustentados por estas. O potencial explicativo da sociologia simmeliana dos “círculos sociais” está em desvendar o mundo social por meio da percepção das complexidades inscritas num momento específico no qual indivíduos estão em interação. Enfatizo que as lentas e microscópicas interações operam como fundamentos explicativos para a análise sociológica simmeliana, segundo a leitura empreendida por Moraes Filho (1983, p. 24), na medida em que abarcam as noções de "proximidade" e de “afastamento”, como “[...] as ‘forças psicológicas’, os ‘fatores espirituais’, que aproximam, unem, distanciam ou separam as pessoas e os grupos.”

Cumpre acentuar que a noção de “afastamento”, a partir de Simmel (1939), responde por sua compreensão acerca da dimensão do "conflito" (kampf) como conteúdo presente nos esquemas de interação e formação dos distintos círculos sociais. Sua sociologia permite a análise acerca das discordâncias, das controvérsias, dos distanciamentos entre indivíduos e grupos, como componentes inerentes aos processos de "sociação”, na qual, a existência de contradições e conflitos, ao contrário de revelar uma oposição explícita à ideia de unidade social, fornecem significado para a permanência de determinadas “formas sociais” (SIMMEL, 1939).

A natureza sociológica do “conflito” em Simmel reside na observação acerca da força integradora que tal fenômeno proporciona aos grupos sociais a partir de afastamentos individuais, que podem indicar uma cisão ou contradição intragrupo, mas que, inevitavelmente, atuam para reconfigurar a estrutura dos círculos sociais. O conflito, entendido como “sociação”, é vislumbrado pelo autor nestes termos: “O conflito está assim destinado a resolver dualismos divergentes, é um modo de conseguir algum tipo de unidade, ainda que através da aniquilação de uma das partes conflitantes” (SIMMEL, 1894 in: MORAES FILHO, 1983c, p. 122).

O recurso analítico dos “círculos sociais” de Simmel fornece instrumentais teóricometodológicos para a compreensão do processo de construção da UENF ao indicar como descobrir os “delicados fios”, através das relações mínimas conflituosas entre os indivíduos, cuja repetição contínua fundamenta todas aquelas grandes formações, tornadas objetivas e que apresentam uma história própria, como por exemplo, o nascimento de uma “universidade pública”. Deste modo, a perspectiva simmeliana potencializa a compreensão sobre as “interações” que tornaram possível a versão final assumida pelo projeto UENF em 1993.

É fundamental deslindar, com base nos apontamentos sociológicos ressaltados, a realização da universidade pública de acordo com os microfundamentos dos acordos e das alianças, dos conflitos e das controvérsias que não obstaculizaram empiricamente aquela empreitada, mas a 
significaram como produto político-social. A análise sobre a construção da UENF deve levar em conta, a partir do que mencionei nesta seção, o painel das “interações” e da formação dos “círculos sociais” que proporcionaram, por exemplo, a emergência da figura pública de Darcy Ribeiro e da construção sócio-política de seu protagonismo no cenário de fundação da universidade.

\section{DARCY RIBEIRO E A UENF EM CAMPOS: SOBRE “INTERAÇÕES” E “CÍRCULOS SOCIAIS"}

A entrada de Darcy Ribeiro nas esteiras de planejamento e implantação da UENF em Campos, no início dos anos de 1990, ocorre por meio de uma interação fundamental para os contornos assumidos pelo projeto da universidade naquele momento: tratava-se do segundo governo de Leonel Brizola para o Estado do Rio de Janeiro (1991-1994). O convite, ato interpessoal baseado numa relação de aproximação, é feito por Brizola a Darcy, para ocupar a posição de Secretário Extraordinário de Programas Especiais da SEEPE, instância projetada para dar prosseguimento à empreitada educacional do primeiro Governo Brizola (1983-1986), no qual Darcy foi vicegovernador, ao continuar a implantação dos CIEPs e elaborar, desta vez, o projeto de fundação e implantação da UENF, segundo o imperativo constitucional de 1989. Darcy afastou-se, para tal, do Senado, sendo substituído por seu suplente, Abdias Nascimento, para assumir a SEEPE (ALVES; LIMA, 2003).

Interessante notar que a interação Darcy-Brizola remontava aos tempos de exílio vividos por ambos os personagens no Uruguai dos anos de 1960, após o Golpe de 1964, quando Darcy Ribeiro e Leonel Brizola mantiveram contato político na adesão às ideologias trabalhistas e nacionalistas de Jango, em vivências intercambiadas por suas trajetórias sensíveis às bandeiras da educação pública e do desenvolvimento nacional. Duas figuras públicas, Darcy e Brizola, que se aproximavam também mediante o magnetismo de suas personalidades políticas. Darcy, um intelectual público forjado a partir da concretização de suas “utopias” no campo da educação, como a UnB e, mais tarde, os CIEPs; e Brizola, o líder carismático em contato direto com as “massas” (BOMENY, 2001).

Em Campos, as figuras de Darcy e Brizola canalizariam as discussões e decisões a respeito do modelo de universidade a ser oficializado pelo governo estadual, a partir do encontro com o personagem Anthony Garotinho, à época prefeito de Campos, em seu primeiro mandato no Executivo Municipal pelo PDT. No ano de 1991, quando Brizola e Darcy assumem a condução do projeto a partir da SEEPE, Garotinho estava em seu terceiro ano de governo na Prefeitura, 
compartilhando no cenário municipal, das mesmas pautas em defesa da educação pública que projetavam as lideranças estaduais de seu partido.

Ilustrativa destas interações foi a realização de um grande comício na Praça São Salvador, no centro da cidade de Campos, ainda na campanha eleitoral para o Governo do Estado do Rio em 1990. Brizola participa do evento ao lado de Darcy Ribeiro e das lideranças pedetistas do município, como Garotinho e Fernando Leite Fernandes, este, então deputado estadual pelo PDT. Indo em direção ao palanque, Brizola pergunta a Garotinho o que deveria incluir em suas promessas de campanha ao "povo campista" e o prefeito responde que a "Universidade do Norte Fluminense" era um projeto urgente para os campistas. Brizola, naquele evento político, prometia à praça lotada a criação da universidade e designava Darcy como mentor do projeto a ser elaborado (ALVES; LIMA, 2003).

O ambiente político, municipal e estadual, dimensionava as demandas em torno da instalação da universidade em Campos enquanto uma bandeira que aproximava distintos segmentos político-partidários. O repertório mobilizado por Garotinho, Brizola e Darcy no referido comício já estivera também potencializado por seu opositor à época, o então governador Moreira Franco pelo PMDB, entre 1987 e 1990, alinhavado também pelo antecessor de Garotinho na Prefeitura, José Carlos Vieira Barbosa, o “Zezé Barbosa”, liderança do mesmo partido. É neste sentido que sublinho o processo de construção da UENF em Campos, quanto ao seu marco legal, a partir de 27 de setembro de 1990, em uma solenidade realizada no auditório do Colégio Nossa Senhora Auxiliadora na cidade de Campos, na qual, diante de uma plateia composta por estudantes, intelectuais, professores, políticos da sociedade campista, Moreira Franco assinava o anteprojeto que seria encaminhado à ALERJ, criando a Universidade Estadual do Norte Fluminense, mediante o embasamento da Emenda Popular de 1989.

A referida Emenda Popular havia sido recentemente aprovada a partir de intensa mobilização dos grupos intelectuais e políticos, movimento legítimo que conseguiu angariar 4.431 assinaturas de cidadãos e cidadãs campistas, objetivando levar a termo jurídico estadual o reclame de construção da universidade em Campos. ${ }^{5}$ Especificamente, o texto da Emenda Popular entregue em 16 de maio de 1989 (registrada como Emenda n 547, em nome da “Comissão Pró-Emenda Popular pela Universidade Estadual do Norte Fluminense”), ao Deputado Estadual Josias Ávila,

\footnotetext{
${ }^{5}$ A Constituição Estadual de 1989, instalada em abril daquele ano, possibilitava a inclusão de “Emendas Populares”, a partir da obtenção de, no mínimo, 3.000 assinaturas como base para o documento. Esta brecha constitucional permitiu que se constituísse uma oportunidade legal para a aprovação do dispositivo que criaria a "Universidade do Norte Fluminense”. Para mais informações, ver Alves e Lima (2003) e Matias (2009).
} 
então presidente da Comissão Constitucional da ALERJ, apresentava como lideranças do documento, nesta ordem: Anthony Garotinho, pela Prefeitura Municipal; Joel Ferreira Mello, pela Associação dos Docentes da Faculdade de Filosofia de Campos (ADOFIC); Renato Barreto de Souza, pela União dos Diretórios Acadêmicos de Campos (UDAC); Mário Lopes Machado, pelo Sindicato dos Professores de Campos e Macaé (SINPROCAM), e; Aristides Augusto Soffiati, pelo Centro Norte Fluminense para Conservação da Natureza (CNFCN) (ALVES; LIMA, 2003; MATIAS, 2009).

O teor do documento que embasava a Emenda Popular de 1989 demonstrava que o clamor em torno da universidade pública a ser criada em Campos não se restringia àquele contexto. É fundamental perceber que os contornos assumidos pelo ideal de instituição propalada pelos círculos intelectuais e políticos locais podem ser capturados enquanto “conteúdos sociais”, se vistos em sua historicidade. Prova disto é que, no texto do documento assinado em 1989, consta como justificativa para a implantação da universidade em Campos um possível "resgate de dívidas acumuladas” por governos estaduais anteriores em relação à região Norte Fluminense.

O movimento mobilizava as interações empreendidas pelo passado político campista, quando, por exemplo, em 1974, o então Governador Raymundo Padilha compareceu à cidade de Campos, em evento realizado na praça em frente à Faculdade de Filosofia, onde assinou um anteprojeto de lei que seria enviado à ALERJ para a criação da universidade em Campos, transformado na Lei n 7399 de 26 de abril de 1974, publicada posteriormente no Diário Oficial. Tal intento seria frustrado, no entanto, devido ao período político turbulento que marcou a fusão do antigo Estado do Rio de Janeiro com a Guanabara, em 1975, o que contribuiu para a desistência do Governo Estadual em rubricar legalmente a construção da universidade em Campos, devido à centralização das ações estaduais em torno da consolidação da UERJ na capital, no mesmo ano (VENANCIO, 2006).

Percebo que a temática da “universidade”, ao ser dotada de conteúdos específicos germinados nas demandas locais, deve ser visualizada segundo o imaginário e as práticas sóciopolíticas dos grupos mais à frente dos debates em torno da implantação da UENF em Campos. Isto porque significada historicamente pelas “interações” e dinamizada pelos mais variados “círculos sociais” formados por aqueles personagens. Neste sentido, vejo que a recorrência do anseio campista pela universidade, - que remonta aos anos de 1930, com o surgimento de suas primeiras 
instituições de ensino superior ${ }^{6}$, sentimento também expresso pela publicação "Universidade para Campos” por Theobaldo Miranda Santos em $1935^{7}$ - esteve situado, sobretudo, numa tentativa de projeção da posição intelectual e política campista no cenário regional e nacional, ambição esta que percorreu todo o século $\mathrm{XX}^{8}$.

Compreendo este panorama através da centralidade dispendida pelas instituições de ensino superior campistas enquanto formadoras dos “círculos sociais” fundamentais para a ampliação e a sistematização do projeto de universidade para Campos defendido por seus representantes. As faculdades campistas de Filosofia, de Direito, de Medicina e de Odontologia, geridas por suas fundações mantenedoras (a Fundação Cultural de Campos e a Fundação Benedito Pereira Nunes), construídas nos anos de 1960 e 1970, protagonizaram o movimento de publicização em torno dos debates sobre a "Universidade para Campos”. Seus professores e professoras, diretores e diretoras, lideraram as ações relativas à redação e aprovação da "Emenda Popular”, estiveram à frente de seminários e eventos organizados em torno da causa, e foram personagens componentes das primeiras comissões de implantação da universidade.

Quando, ainda no final do governo Moreira Franco, em 16 de outubro de 1990, foi promulgada a Lei de Criação da UENF (Lei 1.740, sancionada em 08 de novembro do mesmo ano), a sua primeira comissão especial de implantação esteve composta em sua totalidade pelas personalidades ligadas às instituições de ensino superior campistas: Maria Clara Mattoso e Zuleima de Oliveira Faria, pela Faculdade de Filosofia; Geraldo da Silva Venancio e Oswaldo Cardoso de Mello, pela Faculdade de Medicina; Luiz Cesar Lusitano e Rutílio Caldas Pessanha, pela Faculdade de Odontologia; e Levy Quaresma e Aldano Sellos de Barros, pela Faculdade de Direito (ALVES; LIMA, 2003).

\footnotetext{
${ }^{6}$ De acordo com Venancio (2006), o então deputado campista Mário Barroso propôs, em relação ao projeto da Constituição Estadual de 1935, a incorporação das instituições de ensino superior existentes na cidade à administração do Estado (a Faculdade de Direito Clóvis Bevilácqua e as Faculdades de Agronomia e Veterinária, Farmácia e Odontologia), providenciando, dentro de cinco anos da promulgação da Constituição, a criação da Universidade de Campos, ao integrar as instituições supracitadas.

${ }^{7}$ A publicação “Universidade de Campos: sugestões para a sua organização” foi escrita por Theobaldo Miranda Santos, diretor do Liceu de Humanidades e Escola Normal Oficial de Campos, em 1935, a partir de conferência realizada no Rotary Club de Campos.

${ }^{8}$ O projeto político que ambicionava estabelecer a cidade de Campos como capital do Estado do Rio de Janeiro teve seu apogeu no início do século XX, mais precisamente nas décadas de 1910 e 1920. Em tal momento histórico, a pujança advinda da economia açucareira estruturada a partir do funcionamento do sistema sucroalcooleiro (de produção e comercialização do açúcar) favorecia a tentativa, estrategicamente orientada pelas elites políticas campistas (lideradas por Nilo Peçanha, Presidente da República entre 1909 e 1910), de projeção política do município nas dinâmicas de lutas por poder, nos cenários estadual e nacional. A este respeito, ver Alves (2009).
} 
Entre 1990 e 1991, alguns conteúdos seriam modificados naquilo que dizia respeito à condução do projeto de universidade a ser executado pelo Governo Estadual e clamado pelos círculos envolvidos com a causa universitária na cidade de Campos. O grau de expectativa depositada pelos grupos intelectuais e políticos ligados às faculdades campistas corria na direção daquilo que havia sido manifesto pela Emenda Popular de 1989, assim como articulado com as forças estaduais ligadas ao governo Moreira Franco. Não seria possível desconsiderar, por certo, todo o debate e a experiência acumulada ao longo de anos de envolvimento e de defesa da universidade para Campos. Mas, em se tratando de perceber a "universidade" como "forma social” (a partir de seus múltiplos e distintos “conteúdos”), não haveria consenso previamente estabelecido, entre os personagens atuantes, sobre o projeto de universidade a ser seguido.

\section{“CONFLITOS” E “CONTROVÉRSIAS” EM TORNO DO(S) PROJETO(S) UENF}

O processo de construção da UENF em Campos merece ser desvendado, conforme assinalado antes, a partir da atenção aos “delicados fios”, conforme a acepção simmeliana, dando conta de perceber a natureza dos “conflitos” e “controvérsias” que significaram a experiência histórica de fundação da universidade. Indico que as primeiras controvérsias em torno do projeto de universidade a ser posto em prática aparecem já em 1991, no primeiro ano do segundo Governo Brizola, quando os encaminhamentos relativos à implantação da UENF são iniciados a partir de uma reunião ocorrida em 11 de outubro de 1991, na SEEPE, com a presença de Darcy Ribeiro, representante-chave do governo, e dos personagens que iriam compor as "novas” comissões de implantação da UENF.

Interessante notar os modos pelos quais o tal acontecimento indicou novos rumos ao projeto da universidade para Campos. A referida reunião teve como pauta a implantação da "Universidade Estadual Norte/Noroeste Fluminense - UENF”, denominada nestes termos na escrita da ata, contando como participantes além de Darcy, o então prefeito de Campos, Anthony Garotinho; o deputado estadual pedetista, Fernando Leite Fernandes; João Paulo Dutra de Andrade, à época subsecretário adjunto de planejamento; Ana Lúcia Boynard, então secretária de administração de Campos; Tatiana Memória, vinculada à SEEPE; e Sérgio Pereira da Silva, vinculado à Fundação de Amparo a Escola Pública (FAEP) ${ }^{9}$.

A primeira medida de formalização da construção da UENF pelo Governo Brizola reconfiguraria pontos basilares das estruturas de organização do movimento pró-universidade

\footnotetext{
${ }^{9}$ Documento consultado nas pastas componentes do “Arquivo Darcy Ribeiro - Fundação Darcy Ribeiro”.
} 
atuante no município até 1990, significada, por certo, pelas “interações” e pelos novos “círculos sociais” produzidos nas esteiras de discussão do governo pedetista. A reunião presidida por Darcy alteraria, quase que por completo, a configuração da “comissão especial de implantação”, nomeada por Moreira Franco em seus últimos atos de governo.

As deliberações oficiais indicavam a redação de um Decreto pelo Executivo Estadual criando as "Comissões de Implantação" ${ }^{10}$ da UENF que substituiriam a antiga comissão criada no Governo Moreira Franco, compostas agora por Darcy Ribeiro como presidente; Anthony Garotinho, João Paulo Dutra de Andrade, Ana Lúcia Boynard, Sérgio Pereira da Silva e Everardo Paiva de Andrade, da Faculdade de Filosofia, como membros, e ainda contaria com mais dois integrantes da comissão anterior: Zuleima de Oliveira Faria, pela Faculdade de Filosofia, e Aldano Sellos de Barros, pela Faculdade de Direito ${ }^{11}$.

O fato de que apenas dois personagens tenham permanecido desde a formalização da primeira comissão especial se apresenta como uma problemática importante na configuração do(s) projeto(s) UENF quando da transição Moreira Franco-Brizola. Os círculos campistas temiam ali, segundo os relatos de pesquisa, que toda a luta acumulada em torno da universidade campista fosse desvanecida pelos decretos oficiais do novo Governo Brizola. No entanto, outras três deliberações saídas do referido evento governamental sinalizavam para o nível das aproximações e distanciamentos, face os personagens componentes das novas comissões e de suas motivações em torno da causa.

A primeira dizia respeito à alteração na nomenclatura imputada à nova universidade. A indicação era a redação de um Projeto de Lei que mudaria o nome da "Universidade Alair Ferreira” para “Universidade Estadual do Norte Fluminense”, a cargo do deputado estadual Fernando Leite. Pontuo que Alair Ferreira, político campista falecido à época das discussões das comissões, havia se destacado no cenário político municipal como deputado federal pela antiga Aliança Renovadora Nacional (ARENA), tendo sido presidente da Fundação Cultural de Campos, entidade mantenedora das faculdades, de Filosofia, Direito e Odontologia. O antigo deputado teria sido reconhecido pela primeira comissão especial como um símbolo na história das IES campistas, assim como do debate mais amplo sobre a criação da universidade pública na cidade, sendo, portanto, o personagem legitimamente homenageado com seu nome na marca da instituição. Aquele decreto retiraria, porém, o direito historicamente constituído do líder campista na sigla da universidade,

\footnotetext{
${ }^{10}$ Estas seriam subdivididas em "Comissão Acadêmica” e "Comissão Técnica de Planejamento e Implantação” conforme documento consultado nas pastas componentes do “Arquivo Darcy Ribeiro - Fundação Darcy Ribeiro”.

${ }^{11}$ Documento consultado nas pastas componentes do “Arquivo Darcy Ribeiro - Fundação Darcy Ribeiro”.
} 
representando nas entrelinhas, a controvérsia acerca do não-reconhecimento da contribuição daquele político, e das lideranças intelectuais campistas, para a construção da UENF no cenário local.

O segundo aspecto controverso que consta nos tempos pioneiros de fundação da UENF em Campos é sobre a existência do Instituto de Ciências Humanas, inicialmente previsto no desenho da futura universidade. O encaminhamento partilhado pelos presentes na reunião era de que tal unidade fosse implantada num segundo momento, com o objetivo de não fazer concorrência em relação às faculdades já existentes na cidade (que ofertavam cursos de Direito e Filosofia, por exemplo), evitando, desta forma, o êxodo dos alunos para o ensino gratuito. Ressalto que as instituições privadas de ensino superior campistas que protagonizaram os debates e ações em torno da universidade pública, na medida da expressão política usufruída por seus círculos, se faziam presentes nas instâncias internas de decisão do Governo Brizola, manifestando por dentro do grupo, os conflitos inerentes aos projetos de universidade em disputa naquele cenário.

Os distintos conteúdos sociais se expressavam através das posições dos personagens, portavozes de múltiplas visões sobre a universidade pública, potencializando as interações conflituosas no seio das estruturas administrativas responsáveis pela execução do projeto oficial da universidade, demonstrando assim os aspectos mais sutis e relacionais, internamente à condução do processo oficial de construção da UENF. Isto é o que depreendo enquanto terceiro elemento controverso em torno do(s) projeto(s) em disputa no cenário da fundação da instituição.

Também como encaminhamento prático das primeiras ações do Governo Brizola, um modelo de universidade, reputado como "novo" e “moderno”, estava sendo costurado nas interações lideradas por Darcy Ribeiro nas comissões de implantação. Brizola e Darcy, já ambientados em relação às motivações dos círculos campistas desde o episódio do comício na praça principal da cidade, tinham ciência dos anseios locais em torno da consolidação da "Universidade de Campos”, assim como da centralidade assumida pelos personagens vinculados às faculdades históricas. Em documento extraído da primeira reunião de 1991, tal posição é explicitada nestes termos: "Foi criada uma expectativa fisiológica na comunidade acadêmica que demandará muita habilidade para ser contornada, pois os funcionários pensam que serão incorporados sem concurso à carreira pública [...] A posição do Estado, no entanto, é criar uma universidade de vanguarda e socialmente necessária, em lugar daquela oportuna para um grupo.”12

\footnotetext{
12 Documento consultado nas pastas componentes do “Arquivo Darcy Ribeiro - Fundação Darcy Ribeiro”.
} 
A afirmação de um projeto de universidade entendido como “necessário” pelos círculos participantes das comissões de implantação a partir do Governo Brizola, em alguma medida, flertava com as propostas elaboradas por Darcy Ribeiro desde as suas formulações para o campo universitário brasileiro e latino-americano, das quais sobressaíam, por exemplo, a experiência de fundação da UnB nos anos de 1960. Entretanto, a tentação darcyniana de propor "utopias desvairadas sobre o vazio", como reconhece o próprio Darcy na escrita do "Plano Orientador” da UENF (RIBEIRO, 1993), no que tange à amplitude das ambições dos projetos universitários dos quais participou, convivia inevitavelmente com as estratégias formatadas mediante o entrecruzamento dos variados círculos sociais produzidos e atuantes na esfera das decisões oficiais acerca de qual universidade deveria ser efetivamente “necessária” para Campos e para a região Norte Fluminense (MIGLIEVICH-RIBEIRO; MATIAS, 2006).

Estes gradientes de oposição, entre os grupos políticos e intelectuais campistas e os personagens componentes das comissões oficiais de implantação, sob a responsabilidade de Darcy, devem ser concebidos, porém, de forma relativa, uma vez que não ocorreu uma participação nítida entre os “campistas” e o “grupo de Darcy e Brizola”. Já indiquei, ao longo da exposição, a participação de inúmeros personagens campistas por dentro das comissões de implantação da UENF, ainda que discordâncias e controvérsias tenham sido produzidas a partir das interações entre aqueles grupos no decorrer do tempo histórico. Os conflitos de perspectiva acerca dos projetos de universidade imbricados nas posições, ações e motivações dos múltiplos círculos presentes no processo de construção da UENF foram elementos constitutivos da versão final assumida pela UENF em 1993.

\section{CONSIDERAÇÕES FINAIS}

O processo de construção da Universidade Estadual do Norte Fluminense Darcy Ribeiro (UENF) em Campos dos Goytacazes/RJ merece ser revisitado, sistematicamente, com o fito de compreensão acerca dos caminhos e descaminhos experimentados por uma instituição de ensino superior em sua época de mais tenra idade. ${ }^{13}$ As vivências e motivações, germinadas a partir das

\footnotetext{
${ }^{13}$ Já tendo 25 anos completos de existência institucional, a UENF estruturada em seus quatro centros de ensino, pesquisa e extensão (Centro de Ciências do Homem (CCH), Centro de Biociências e Biotecnologia (CBB), Centro de Ciência e Tecnologia (CCT) e Centro de Ciências e Tecnologias Agropecuárias (CCTA), tem merecido destaque, ao longo de seu percurso, por seu perfil de formação acadêmica e científica, pautado pela excelência, em níveis de graduação e de pós-graduação. Simultaneamente, a instituição tem enfrentado um quadro conjuntural de aprofundamento do desmonte do sistema educacional público estadual levado a cabo por consecutivos governos, inviabilizando a manutenção de atividades básicas (como serviços de limpeza e de segurança em seu campus) por vários semestres letivos. Para mais informações, sobre a história uenfiana recente, ver Smiderle e Muylaert (2013).
} 
interações dos diversos personagens presentes no ambiente de fundação da universidade, preenchem de sentido o quadro sociológico que se deseja elaborar, com vistas à investigação sensível às relações sociais mais finas que sustentam a sua dimensão propriamente institucional. De acordo com a acepção simmeliana, a qual interpelei brevemente, estas respondem pelos “conteúdos” significantes dos desenhos assumidos pelas feições e modelos de universidade, uma vez que ultrapassavam discussões pautadas pelo "personalismo” de um ou outro, para expressarem, concretamente, projetos de universidade pública que seriam reputados como "necessários” para Campos, na visão dos personagens componentes dos “círculos sociais” presentes no início da história da UENF.

Assim, pude expor alguns acontecimentos que fundamentaram os tempos dos pioneiros e das pioneiras da formação da UENF na cidade de Campos e na região Norte Fluminense, para os quais não havia um único projeto exato, e portanto consensual, a ser buscado e efetivado no mundo das coisas. Antes, o período de construção da UENF precisa ser matizado segundo o nível das “interações” empreendidas por vários indivíduos e grupos, produtores de seus “círculos sociais”, a fim de compreender as formas pelas quais os dois projetos de universidade, mais nítidos em tal moldura, também estiveram em “interação” no início dos anos de 1990: um, predominantemente arraigado nas formas de ver e sentir o tema da universidade em Campos, historicamente defendido pelos grupos políticos e intelectuais campistas e suas instituições de ensino, para o qual a "Emenda Popular” de 1989 representou a expressão mais bem sucedida; e outro que, assumido em seus perfis “modernizantes”, de aposta na produção científica e tecnológica como missão universitária, emergiu dos debates internos das comissões de implantação a partir de 1991, para as quais a relevância imputada à Darcy Ribeiro não pode ser descartada.

Os “conflitos” e “controvérsias” que puderam ser dimensionados quando da “aproximação” dos distintos personagens, revelaram o ponto crucial em que ocorreu o entrecruzamento destes mesmos círculos sociais, assim como deram o tom dos níveis de “afastamento” verificados entre os grupos participantes da época de institucionalização de um projeto universitário na realidade efetiva. Nestes termos, a “versão final” assumida pelo documento fundador da UENF, em agosto de 1993, aparece como produto de uma série complexa de interações, compostas por todos e por todas que forneceram significado a partir de suas vivências devotadas à causa da universidade pública em Campos, sobre a qual ainda se pode debruçar em nome de caminhos mais justos e democráticos a serem desbravados. 


\section{REFERÊNCIAS}

ALVES, H. A Sultana do Paraíba. Reformas urbanas e poder político em Campos dos Goytacazes 1890-1930. Rio de Janeiro: Arquivo Público do Estado do Rio de Janeiro, 2009. 206p.

; LIMA, L. UENF, a Universidade do Terceiro Milênio: uma memória (1993-2003). Campos dos Goytacazes: UENF, 2003. 144p.

BOMENY, H. Darcy Ribeiro. Sociologia de um indisciplinado. Belo Horizonte: UFMG, 2001. 284p.

MATIAS, G. A superação do atraso como “mudança provocada”: a contribuição de Darcy Ribeiro para o debate sobre a mudança social na sociologia brasileira. Agenda Social, Campos dos Goytacazes, n. 2, p. 22-39, mai. 2008.

. A utopia é de concreto: círculos sociais e a construção da UENF em Campos dos Goytacazes/RJ. Dissertação (Mestrado em Sociologia) - Universidade Federal do Rio de Janeiro, Rio de Janeiro, 2009.

MIGLIEVICH-RIBEIRO, A.; MATIAS, G. A Universidade Necessária em Darcy Ribeiro: notas sobre um pensamento utópico. Ciências Sociais Unisinos, São Leopoldo, n. 3, p. 199-205, set. 2006.

MORAES FILHO, E. Formalismo Sociológico e a Teoria do Conflito. In: Simmel. Sociologia. São Paulo: Ática, 1983. p. 7-44.

RIBEIRO, D. Revista Universidade do $3^{\circ}$ Milênio, Campos dos Goytacazes: UENF, v.1, 1993. 65p.

. A Universidade Necessária. 4. ed. Rio de Janeiro: Paz e Terra, 1982. 307p.

SANTOS, T. Universidade de Campos. Sugestões para sua organização. Oficinas Gráficas da Escola do Trabalho: Niterói, 1935. 30p.

SIMMEL, G. Sociologia. Estúdios sobre las Formas de Socialización. Buenos Aires: Espasa-Calpe Argentina, 1939. 359p. p.59-78.

O problema da sociologia. In: MORAES FILHO, E. (Org.). Simmel. Sociologia. São Paulo: Ática, 1983a,

Como as formas sociais se mantêm. In: MORAES FILHO, E. (Org.). Simmel. Sociologia. São Paulo: Ática, 1983b, p.46-58.

A natureza sociológica do conflito. In: MORAES FILHO, E. (Org.). Simmel. Sociologia. São Paulo: Ática, 1983c, p.122-134.

SMIDERLE, G. UENF e Campos, Encontro de dois mundos: uma etnografia da interação entre a coletividade da Universidade Estadual do Norte Fluminense Darcy Ribeiro e a sociedade de Campos dos Goytacazes (RJ), 2002-2004. Dissertação (Mestrado em Políticas Sociais) - Universidade Estadual do Norte Fluminense Darcy Ribeiro, Campos dos Goytacazes, 2004.

; MUYLAERT, F. Uma Casa, muitas vozes: histórias dos primeiros 20 anos da UENF. Campos dos Goytacazes: EDUENF, 2013.144p.

VENANCIO, M. Durante a travessia: memórias e histórias da Faculdade de Filosofia de Campos. Campos dos Goytacazes: Editora da FAFIC, 2006. 240p. 


\section{RESUMO}

Analiso o processo de construção da Universidade Estadual do Norte Fluminense Darcy Ribeiro (UENF) em Campos dos Goytacazes/RJ , em 1993, observando, a partir da dinâmica das interações e do entrecruzamento de diversos "círculos sociais" segundo Georg Simmel, os conflitos e controvérsias impressas nas relações entre os grupos intelectuais e políticos envolvidos com o movimento singular de fundação de uma universidade pública a apostar na Ciência e na Tecnologia para promover o desenvolvimento regional e nacional.

Palavras-chave: UENF. Darcy Ribeiro. Círculos Sociais.

\section{BACK TO THE “THIRD MILLENNIUM”: SOCIAL CIRCLES IN THE CONSTRUCTION OF UENF IN CAMPOS DOS GOYTACAZES}

\section{ABSTRACT}

I analyze the process of building the State University of North Fluminense Darcy Ribeiro (UENF) in Campos dos Goytacazes/RJ, in 1993, observing the dynamics of the interaction and interweaving of different "social circles" as appointed by Georg Simmel, conflicts and controversies in the relationship between the intellectuals and politicians groups involved with the movement of foundation of a public university focusing on science and technology to promote regional and national development.

Keywords: UENF. Darcy Ribeiro. Social Circles.

\section{DE VUELTA AL “TERCER MILENIO”: CÍRCULOS SOCIALES EN LA CONSTRUCCIÓN DE LA UENF EN CAMPOS DOS GOYTACAZES}

\section{RESUMEN}

Analizo el proceso de construcción de la Universidad Estatal del Norte Fluminense Darcy Ribeiro (UENF) en Campos dos Goytacazes/RJ, em 1993, observando en la dinámica de las interacciones y de los entrecruzamientos de diversos "círculos sociales", según Georg Simmel, los conflictos y controversias impresas en las relaciones entre los grupos intelectuales y políticos involucrados con el movimiento singular de fundación de una universidad pública, apostando por la Ciencia y la Tecnología para promover el desarrollo regional y nacional.

Palabras clave: UENF. Darcy Ribeiro. Círculos Sociales. 